\title{
Uso da Ferramenta Kahoot Transformando a Aula do Ensino Médio em um Game de Conhecimento
}

\author{
Ernane Rosa Martins' ${ }^{1}$ Luís Manuel Borges Gouveia² \\ ${ }^{1}$ Instituto Federal de Goiás (IFG) \\ Caixa Postal 72.811-580 - Luziânia - GO - Brasil \\ ${ }^{2}$ Universidade Fernando Pessoa (UFP) \\ Caixa Postal 4249-004 - Porto - Portugal \\ ernane.martinseifg.edu.br, lmbg@ufp.edu.pt
}

\begin{abstract}
This article aims to present an activity elaborated on the Kahoot digital platform and analyzes its potential in learning. Kahoot was used to insert an interactive technological resource that appropriates elements of the games (gamification) seeking to engage students in learning. This activity was applied to sixty-eight students from the subjects of web programming and web authoring of the technical course in computer science for the Internet. It was found through the student reports and observations that this activity can improve learning.
\end{abstract}

Resumo. Este artigo visa apresentar uma atividade elaborada na plataforma digital Kahoot e analisa seu potencial na aprendizagem. O Kahoot foi utilizado para inserir um recurso tecnológico interativo que se apropria de elementos dos jogos (gamificação) buscando engajar os alunos na aprendizagem. Essa atividade foi aplicada para sessenta e oito alunos das disciplinas de programação web e autoria web do curso técnico em informática para Internet. Constatou-se por meio dos relatos dos alunos e observações que esta atividade pode melhorar a aprendizagem.

\section{Introdução}

Os alunos que pertencem à "geração digital", que nasceram em meio as tecnologias, apresentam fácil acesso a smartphones e outros aparelhos conectados à Internet, para estes a informação está sempre disponível e acreditam que cada vez menos necessitam do professor para transferência de informações. Os professores que continuam querendo transmitir o conhecimento integral, estão cada vez mais encontrando alunos desinteressados, desatentos e desmotivados, que não enxergam o propósito de ir à aula em busca de conhecimentos (Tardif, 2011).

A gamificação consiste no uso de elementos dos jogos, fora do contexto dos jogos, como por exemplo na educação (Coil et al., 2017), permitindo agregar valor às aulas, proporcionar desafio, prazer e entretenimento na transmissão do conhecimento. Neste contexto, Amico et al. (2017), considera importante avaliar ferramentas como o Kahoot bem como outras plataformas oriundas da gamificação, devido a estas demonstrarem potencial para se tornarem tendências consolidadas na área da educação. Emergem, na contemporaneidade, diversas abordagens e possibilidades para a ampliação das ações pedagógicas em sala de aula, assim como seu potencial (Figueiredo, Paz \& Junqueira, 2015). Gazotti-Vallim (2017), afirma que o uso de tecnologias digitais de informação e comunicação, bem como de metodologias ativas e gamificação na escola têm sido alvo de muita discussão. Essas estratégias têm provado 
VIII Congresso Brasileiro de Informática na Educação (CBIE 2019)

Anais do XXV Workshop de Informática na Escola (WIE 2019)

sua eficiência em atrair os estudantes, permitindo assim, uma melhora em seu desempenho acadêmico, social e cognitivo.

Sendo assim, este trabalho apresenta um relato de experiência de uma atividade elaborada na plataforma digital Kahoot e a análise de seu potencial na aprendizagem dos alunos. Este artigo está estruturado em sete seções. Nesta presente seção apresenta, além da introdução, a definição da problemática de pesquisa, o objetivo, a justificativa e importância do estudo e a estrutura da presente pesquisa. Na seção 2 é contextualizado o Kahoot. A seção 3 aborda a gamificação na educação. A seção 4 apresenta os principais trabalhos relacionados. Na seção 5 são descritos o método empregado e os procedimentos metodológicos utilizados. $\mathrm{Na}$ seção 6 estão descritos os resultados obtidos na pesquisa e discussão. Por fim, a seção 7 retoma o objetivo do artigo, como ele foi alcançado e propõe sugestões de pesquisas futuras.

\section{Kahoot}

O Kahoot é uma plataforma de aprendizagem gratuita baseada em jogos que tem como missão institucional descrita em seu site como "desbloquear o potencial mais profundo de cada aluno de todas as idades e em todos os contextos, através de um aprendizado divertido, mágico, inclusivo e envolvente" (Kahoot, 2018). Esta plataforma permite criar questionários, discussões ou pesquisas que podem ser respondidas por usuários que estejam conectados à Internet por meio de smartphones ou computadores. Para sua utilização, faz necessário a realização de um cadastro na plataforma de ensino virtual (https://kahoot.com/).

A proposta do Kahoot é envolver os alunos por meio de questionários, discussões e pesquisas pré-elaboradas semelhantes a jogos, com pontuação, interação e ranqueamento (Dellos, 2015). Os alunos não precisam ter uma conta para utilizar o Kahoot. Para entrar, eles devem inserir um pin e um apelido. Ao iniciar, as perguntas junto com as respostas são mostradas na tela grande, e os alunos pressionam a mesma cor e símbolo com a resposta que eles acreditam ser a correta na tela do celular. É exibido um cronômetro, que vai diminuindo até zero, assim como o número de alunos que vão respondendo às perguntas. Ao mesmo tempo, os alunos recebem feedback individual sobre como responderam em seus dispositivos.

As respostas dos alunos fornecem ao professor feedback sobre a compreensão dos alunos sobre a questão, e cria uma oportunidade para discussão sobre a questão e as respostas. O placar dos cinco melhores, com os pontos e apelidos, é mostrado entre as perguntas. Cada aluno também pode seguir sua própria pontuação e ranking no próprio dispositivo móvel. Para obter uma pontuação alta, os alunos precisam responder corretamente e rapidamente as perguntas. Música e efeitos sonoros são usados no Kahoot para criar suspense e atmosfera de um game show (Wang, 2015). A ideia principal do Kahoot é ser uma plataforma onde o professor e o os alunos podem interagir em sala de aula simulando um jogo de conhecimento competitivo. A motivação é envolver os alunos através da transformação da sala de aula em um game show, onde o professor seria o apresentador e todos os alunos podem competir ganhando pontos através de respostas corretas em várias questões relacionadas ao assunto que está sendo ensinado na aula (Wang, 2015). 
O Kahoot utiliza três técnicas de gamificação: pontuação, limite de tempo e placar de pontos, mas deixa de fora várias outras técnicas que poderiam ser aproveitadas, tais como: medalhas, progressão, objetivos em longo prazo, mecânicas variadas, entre outras (Faria, Costa \& Parreira Júnior, 2016). Há na literatura recente alguns exemplos de trabalhos que aplicam a gamificação com uso da plataforma Kahoot, tais como: Dellos, 2015; Rodríguez-Fernández, 2017; Yapici \& Karakoyun, 2017 e Romio \& Paiva (2017). Estes apresentaram por exemplo a postura positiva dos alunos, a geração de interesse, a motivação e atenção apresentadas com a utilização da ferramenta.

\section{Gamificação na Educação}

Os jogos, tanto em consoles, smartphones ou computadores, são de grande aceitação no contexto da popularização das tecnologias. Assim, a utilização dos jogos no ensino apresenta grandes vantagens, tais como: interatividade, superação de desafios, metas e objetivos em conjunto com um nível elevado de envolvimento e motivação (Pereira \& Pimentel, 2014). Deterding et al. (2011, p.11), define gamificação como o uso de elementos do design de jogos em contextos diferentes dos de jogos. Os autores dizem também que, apesar da grande maioria de exemplos de aplicação da gamificação ser digital, o termo não deve ser limitado apenas a tecnologias digitais.

A utilização da gamificação em práticas educacionais conforme Kapp (2012), é definido como "o uso de mecânica (as regras, o feedback, os níveis, as recompensas e o placar), estética (design do game com uma interface atraente) e pensamento dos games (construção de experiências agradáveis, sentimento de realização, competição, conflito, cooperação) para envolver pessoas, motivar a ação, promover a aprendizagem e resolver problemas". Esta estratégia tem como princípio a utilização de um ambiente em que os alunos possam realizar suas atividades de forma motivadora, aplicando elementos como: competição, exploração, cooperação e narrativa diferenciada. A estratégia potencializa a aprendizagem por meio de um conjunto de elementos dos games, afim de gerar um envolvimento e uma dedicação semelhante à que os games propiciam aos seus jogadores. A gamificação busca envolver as pessoas em um nível emocional e motiválas a alcançar metas estabelecidas.

Os sistemas gamificados hierarquizam o processo de aprendizagem, criando níveis de dificuldade progressivos, semelhante aos games. Assim, em cada um dos níveis, o aluno desenvolve novas habilidades para atingir as etapas seguintes. Assim a aprendizagem acontece de forma progressiva, onde habilidades e conhecimentos são construídos a partir do que foi aprendido anteriormente (Burke, 2015). Para Kapp (2012), a gamificação quando bem projetada, pode ajudar os alunos a adquirirem habilidades, conhecimentos e competências em um período curto de tempo, com uma alta taxa de retenção do conteúdo. As publicações referentes a temática da gamificação na educação aponta diversos motivos para sua adoção, quando bem planejada, sendo os principais deles: permitir o feedback constante e em ciclos mais curtos, favorecendo a aprendizagem mais rápida; melhorar a retenção e criação do conhecimento; aumentar a percepção de realização individual e coletiva; aumentar o engajamento; reforçar a aprendizagem e desenvolvimento (Dicheva et al., 2015; Domínguez et al., 2013; Morrison \& Disalvo, 2014). 
VIII Congresso Brasileiro de Informática na Educação (CBIE 2019)

Anais do XXV Workshop de Informática na Escola (WIE 2019)

Lee \& Hammer (2011) apresentam vantagens e desvantagens do uso da gamificação na educação, podendo motivar os alunos a se envolverem com a sala de aula, dar aos professores melhores ferramentas para orientar e recompensar os alunos, incentivar os alunos a manterem uma aprendizagem para a vida toda, além de poder vir a ser uma experiência divertida. Entre as possíveis desvantagens, quando a gamificação é mal utilizada na educação, temos: no caso dos alunos pensarem que devem aprender apenas quando forem receber algum tipo de recompensa externa. Gamificação é uma ferramenta multidisciplinar que engloba vários domínios, teorias de pensamentos, metodologias, e várias razões para sua implementação. Os seres humanos são fortemente atraídos pelos jogos (Rocha et al., 2016).

\section{Trabalhos Relacionados}

No trabalho de Sande \& Sande (2018) intitulado "Uso do Kahoot como ferramenta de avaliação e ensino-aprendizagem no ensino de microbiologia industrial", os autores aplicaram um quiz usando a plataforma Kahoot como estratégia de avaliação e ensinoaprendizagem na disciplina de Microbiologia Industrial. Os alunos realizaram a atividade avaliativa e em seguida responderam a um questionário através de um formulário do GoogleDocs. Os alunos citaram a competição como estímulo para o aprendizado e perceberam que o kahoot pode ser usado como substituto da avaliação tradicional uma vez que consegue alcançar diferentes níveis de complexidade que desafiam os alunos e tornam o aprendizado mais eficiente e duradouro.

Alves \& Roza (2018), no trabalho intitulado "Gamificação no ensino de administração: o uso da plataforma Kahoot em uma disciplina de gestão de projetos", relatam uma experiência de gamificação com a utilização da plataforma Kahoot, envolvendo 20 questões, em formato de quiz, aplicada aos alunos da disciplina de gerenciamento de projetos de um curso superior de administração em uma instituição de ensino privada. O questionário foi respondido como revisão para a prova e duas turmas realizaram o quiz. Duas turmas realizaram o jogo, uma com 11 alunos com aproveitamento de $56,02 \%$ e outra com 16 alunos e desempenho de 58,63\%. Os resultados foram considerados regulares, alertando os alunos para a necessidade de maior estudo como preparação para a prova. Os fundamentos de design de jogos foram seguidos pela aplicação do game em relação às regras, resultados quantificáveis, o esforço do aluno, a emoção, em conjunto com a trilha sonora, para impulsionar os alunos ao acerto.

No trabalho de Perez et al. (2018), intitulado "Kahoot como ferramenta de revisão de conteúdo em neurociências", relatam a implementação do Kahoot na disciplina de Neurociências como estratégia de revisão de conteúdos antes da prova discursiva nos cursos de graduação em Biomedicina e Fonoaudiologia da Universidade Federal Fluminense (Campus Nova Friburgo). As questões foram elaboradas pelos estudantes em grupos conforme os temas de aula que seriam cobrados na prova discursiva, revisadas pelo docente e inseridas no Kahoot pelo monitor. No dia da aplicação do Kahoot, as questões foram projetadas no quadro branco e os estudantes responderam às questões em grupo através de seus dispositivos móveis. Como resultado, notou-se grande interação entre o docente e os estudantes, assim como entre os estudantes na discussão das alternativas de resposta. $\mathrm{O}$ desempenho dos grupos foi satisfatório, demandando pouco tempo para responder às questões. O Kahoot gera um 
VIII Congresso Brasileiro de Informática na Educação (CBIE 2019)

Anais do XXV Workshop de Informática na Escola (WIE 2019)

rank em tempo real dos grupos e acertos e isso motivou os estudantes a se empenharem na atividade para ficar na primeira colocação.

Silva et al. (2018), no trabalho "Tecnologias digitais e metodologias ativas na escola: o contributo do Kahoot para gamificar a sala de aula", descrevem as contribuições do Kahoot para facilitar o processo de gamificação da sala de aula. Para tanto, realizou-se um estudo de caso descritivo de natureza qualitativa com alunos do Ensino Médio. Os instrumentos de coleta de dados utilizados foram observação e questionários on-line (Quizzes). Os resultados apontaram que o Kahoot potencializou o uso da gamificação em sala de aula por facilitar a utilização de elementos de games como feedback imediato, regras claras, diversão, inclusão do erro, prazer e motivação.

\section{Metodologia}

Nesta seção apresentamos a metodologia utilizada, que foi o estudo de caso, com os instrumentos: observação direta das interações e as reflexões e percepções dos alunos. A pesquisa foi aplicada para sessenta e oito alunos das disciplinas de programação web e autoria web do curso técnico em informática para Internet. Todos os alunos relataram que possuíam smartphone e utilizariam a Internet da instituição para a realização da atividade. A atividade teve vinte e cinco questões, com duração total de uma hora e trinta minutos, onde foram cadastradas questões relativas ao conteúdo da disciplina.

Segundo Yin (2003), os estudos de caso descrevem um fenômeno ou intervenção no contexto em que ocorre. A revisão bibliográfica permitiu levantar informações sobre o assunto e ajudou na formulação das perguntas da pesquisa. Ao final da atividade com o Kahoot foi aplicado um questionário eletrônico do Google Docs com cinco perguntas abertas e duas fechadas, preenchidas individualmente, sendo elas: Quais as limitações do uso da tecnologia móvel no processo de aprendizagem? Como o uso do aplicativo durante a atividade contribuiu para a sua aprendizagem? Quais os pontos positivos na utilização de tecnologias móveis no processo de aprendizagem? Quais os pontos negativos na utilização de tecnologias móveis no processo de aprendizagem? Quais as suas sugestões em relação à atividade? Qual o seu nível de satisfação em relação a metodologia utilizada na atividade? Qual o seu nível de satisfação em relação ao aplicativo utilizado na atividade?

Os objetivos dessa pesquisa são de caráter exploratórios e descritivos. Exploratórios pois permitirá uma maior proximidade entre o pesquisador e o problema, possibilitando aprimorar ideias ou a descoberta de novas intuições, e descritiva pois serão expostas algumas características apresentadas pelos alunos. A análise de conteúdo foi aplicada aos dados coletados a partir das perguntas abertas. Segundo Trivinos (1987), a análise de conteúdo é considerada um "conjunto de técnicas" que envolve a classificação dos conceitos, a codificação dos mesmos e a categorização. Assim, cada resposta foi lida mais de uma vez, codificada e foi criada uma tabela de frequência. Os temas foram identificados e, por último, a harmonização de códigos e temas foi examinada. As declarações significativas dos participantes foram incluídas como citações para ilustrar. As respostas fechadas foram tabuladas com o software Excel, e posteriormente analisadas. 
VIII Congresso Brasileiro de Informática na Educação (CBIE 2019)

Anais do XXV Workshop de Informática na Escola (WIE 2019)

\section{Resultados e Discussões}

Nesta seção são descritos os resultados obtidos na pesquisa, conforme ilustra a Tabela 1 e as Figuras 1 e 2.

Tabela 1. Perguntas aplicadas aos alunos e suas respostas.

\begin{tabular}{|c|c|}
\hline Perguntas & Respostas dos Alunos \\
\hline $\begin{array}{l}\text { Quais as limitações } \\
\text { do uso da tecnologia } \\
\text { móvel no processo de } \\
\text { aprendizagem? }\end{array}$ & $\begin{array}{l}\text { Alguns podem não tem celulares tão avançados ou falta de bateria no smartphone } \\
\text { e ficam de fora; A falta ou a velocidade da Internet; Pode dispersar muito, distrair } \\
\text { do verdadeiro objetivo em sala de aula; Falhas técnicas; Nenhuma; }\end{array}$ \\
\hline $\begin{array}{l}\text { Como o uso do } \\
\text { aplicativo durante a } \\
\text { atividade contribuiu } \\
\text { para a } \\
\text { aprendizagem? }\end{array}$ & $\begin{array}{l}\text { Competição ajuda muito; Através do celular foi possível realizar a atividade é } \\
\text { testar seus conhecimentos interagindo com a turma; Deixou mais fácil o acesso ao } \\
\text { conteúdo que estava sendo estudado; Acho legal e criativo; Eu gostei, traz } \\
\text { interação com a turma e o debate sobre o conteúdo; Ajuda a ter mais atenção; Foi } \\
\text { divertido, contribui de forma dinâmica e desperta o lado competitivo; É mais } \\
\text { produtivo; Ajudou na interação com os demais colegas e o professor e a aumentar } \\
\text { o interesse dos alunos; Um jogo de perguntas rápidas ajuda você no seu } \\
\text { aprendizado; Fica divertido e competitivo, faz com que o interesse na matéria } \\
\text { seja maior; Ajudou na revisão da matéria passada; Facilitou minha fixação do } \\
\text { conteúdo por ser uma forma fácil e divertida de revisar; Contribuiu muito; }\end{array}$ \\
\hline $\begin{array}{lr}\text { Quais os } & \text { pontos } \\
\text { positivos } & \text { na } \\
\text { utilização } & \text { de } \\
\text { tecnologias } & \text { móveis } \\
\text { no processo } & \text { de } \\
\text { aprendizagem? } & \end{array}$ & $\begin{array}{l}\text { A aprendizagem fica mais fácil e lúdica; Divertido, prático, rápido e com maior } \\
\text { interação dos alunos; Um jeito mais fácil de fazer pesquisas, comunicação, etc.; } \\
\text { Deixar o aluno interessado ficamos } 100 \% \text { acordados; Acesso a mais conteúdo; É } \\
\text { realizado de uma forma mais descontraída; Maior facilidade de aprendizagem, } \\
\text { facilidade de comunicação e estudo; É uma forma de testar meus conhecimentos; } \\
\text { A facilidade e a rapidez em acessar alguma coisa; A dinâmica e o interesse do } \\
\text { aluno serem maiores, a relação entre aluno e professor ser mais interativa; } \\
\text { Deixam as aulas mais intuitivas; Aumenta a comunicação, aprendizado e } \\
\text { diversidade didática; Mais familiarização, tecnologia acessível, é divertido e } \\
\text { didático; Motivação para pesquisar sobre o assunto e animação para frequentar a } \\
\text { aula; }\end{array}$ \\
\hline $\begin{array}{lr}\text { Quais os } & \text { pontos } \\
\text { negativos } & \text { na } \\
\text { utilização } & \text { de } \\
\text { tecnologias móveis } \\
\text { no processo de } \\
\text { aprendizagem? }\end{array}$ & $\begin{array}{l}\text { Não vejo pontos negativos; O caso do uso de outros aplicativos ou redes sociais } \\
\text { que não tem nada a ver com a aula e pode distrair alguns alunos; Falhas } \\
\text { tecnológicas, não têm celular bom, Internet lenta, bateria fraca, as vezes pode } \\
\text { acontecer de travar e atrapalhar o aluno; Ás vezes nos prendemos mais à } \\
\text { competição do que ao conteúdo; } \\
\text { Tempo estabelecido; O compromisso em usar o aparelho para aquela finalidade } \\
\text { as vezes não é cumprido, já que é fácil a dispersão com outros softwares } \\
\text { presentes no celular; }\end{array}$ \\
\hline $\begin{array}{l}\text { Quais as suas } \\
\text { sugestões em relação } \\
\text { à atividade? }\end{array}$ & $\begin{array}{l}\text { Realizar mais vezes com outros assuntos; Deveria valer ponto; O jogo poderia } \\
\text { não precisar de Internet para carregar, pois trava muito; Gostaria que tivesse } \\
\text { mais, porém com um maior tempo; Fazer mais atividades em grupo que permita a } \\
\text { utilização do celular. }\end{array}$ \\
\hline
\end{tabular}

Os alunos avaliaram a ferramenta Kahoot como interessante, principalmente por causa da competitividade intrínseca do jogo. Isso demonstra a importância de inserir jogos no ensino. Dellos (2015) corrobora dizendo que essa competitividade do jogo torna a experiência do aprendizado mais valiosa para os alunos. Também é importante o impacto positivo que promoveu nas interações entre os alunos, bem como entre o professor e os alunos. E todos os alunos concordaram que o tempo passou mais rápido do que em uma aula tradicional. Dellos (2015) afirma ainda que o Kahoot é um jogo que possibilita maior interação entre os alunos, envolvendo e incentivando eles a não desistirem facilmente das dificuldades encontradas nas disciplinas. 
VIII Congresso Brasileiro de Informática na Educação (CBIE 2019)

Anais do XXV Workshop de Informática na Escola (WIE 2019)

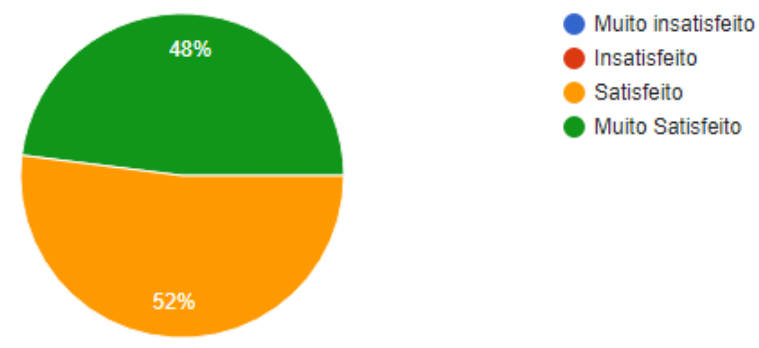

Figura 1. Nível de satisfação em relação a metodologia utilizada na atividade.

A Figura 1, indica que a grande maioria teve uma boa aceitação da metodologia utilizada. Observando a Figura 2, fica claro que foi pouca a insatisfação com o aplicativo utilizado, os alunos insatisfeitos justificaram a resposta por sentirem-se prejudicados por problemas técnicos ocorridos, tais como: quedas na disponibilidade da rede sem fio de Internet local ou falta de carga suficiente na bateria dos aparelhos celulares.

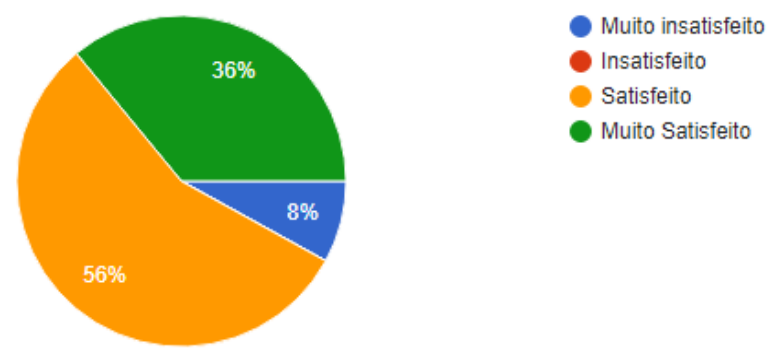

Figura 2. Nível de satisfação em relação ao aplicativo utilizado na atividade.

Foi observado pelo professor que a música e a pontuação apresentada a cada questão fazem com que o jogo se torne mais estimulante. Confirmando o estudo de Wang (2015) que avaliou a concentração, o aproveitamento, o engajamento e a diversão dos alunos jogando Kahoot utilizando ou não o áudio e a pontuação, sendo que quando não utilizou áudio e pontuação, os alunos não mantiveram o foco e a concentração da mesma forma. A apresentação da pontuação em cada questão fez com que os alunos se mantivessem mais concentrados e engajados com o jogo, aumentando assim a competividade. Mostrando que a música e pontos, podem influenciar de maneira significativa no aprendizado.

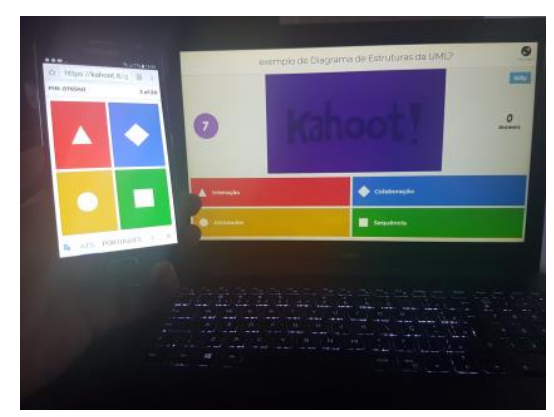

Figura 3. Como os alunos fornecem as respostas no Kahoot com o smartphones. 
VIII Congresso Brasileiro de Informática na Educação (CBIE 2019)

Anais do XXV Workshop de Informática na Escola (WIE 2019)

A criação do jogo foi fácil e o site é praticamente autoexplicativo. Assim, não foi difícil inserir as questões. Entretanto percebeu-se que a disponibilidade de acesso à Internet é fundamental para a utilização da ferramenta. Pode acontecer também do aluno sair acidentalmente do jogo, e ao realizar um novo acesso é feito como se fosse um novo usuário com o mesmo nome do anterior, mas a pontuação não é acumulada. Outra limitação constatada é o limite de caracteres apresentado na elaboração das perguntas, necessitando elaborar perguntas menores.

A Figura 3 demostra como os alunos fornecem suas respostas por meio do aparelho de celular no Kahoot. Na tela grande são mostradas as perguntas e respostas cadastradas pelo professor, e ao mesmo tempo na tela do celular dos alunos aparecem as opções com as mesmas cores e símbolos das respostas. É exibido um cronômetro, que vai diminuindo até zero, e para obter maior pontuação, os alunos precisam responder corretamente e rapidamente as perguntas.

O maior benefício observado nesta experiência, foi o feedback individual que os alunos recebem em seus dispositivos sobre como responderam às perguntas e o feedback que o professor recebe sobre a compreensão dos alunos sobre cada questão, criando ótimas oportunidades para discussões sobre as questões e as respostas. Durante o jogo, os alunos mantiveram-se bastante focados e apreensivos. Respondiam as questões com agilidade, e ao final de cada questão, era analisado quantos tinham respondido certo cada alternativa e porque as outras respostas estavam erradas, os grupos que acertavam, vibravam e todos buscavam tornar-se mais competitivos.

Quando os grupos estavam com pontuações semelhantes, eles tentavam responder de forma mais rápida a próxima questão para ultrapassar o outro grupo concorrente. Este estudo confirma Wang (2015) que observou um aumento significativo no engajamento dos alunos que utilizaram o Kahoot em sala de aula. Além disso, grande parte dos alunos participantes consideraram que o software deixou as aulas mais divertidas e motivadoras. Quanto as respostas dos alunos utilizando a ferramenta, como no Kahoot, os resultados são registrados, verificou que a turma apresentou um aproveitamento de 59,08\% de respostas corretas. Para o professor da disciplina, o percentual de desempenho apresentado pela ferramenta pode servir para mostrar que os alunos precisam ou não estudar mais determinados conteúdos. Para os alunos, estas informações podem servir de referência para comparação do seu desempenho individual em relação à turma.

Em relação à média das notas dos alunos comparando com a média das notas da turma do ano anterior, observou-se que quando os alunos não utilizaram o Kahoot, a média da turma foi 6,1 , enquanto com a utilização da ferramenta a média foi de 7,9 no mesmo período. Apesar de que essa observação não serve como comprovação de que foi somente a utilização da ferramenta que influenciou diretamente no rendimento acadêmico da turma.

Conforme Santaella \& Feitoza (2009), os alunos quando no papel de jogadores, se esforçam para obterem um melhor aproveitamento e melhorarem a sua posição na classificação geral. Criando um envolvimento emocional, que estimula o aluno a se destacar junto ao grupo. Os alunos que obtém as melhores pontuações comemoram o desempenho, e os demais se sentem incomodados e buscam melhorar suas pontuações. Assim, os alunos identificam seus erros e são estimulados a se preparar melhor para os 
VIII Congresso Brasileiro de Informática na Educação (CBIE 2019)

Anais do XXV Workshop de Informática na Escola (WIE 2019)

próximos desafios. Observou-se a possibilidade da utilização do Kahoot para introdução de novos conceitos, por gerar uma descontração entre os alunos criando um clima de aproximação. Além disso, a plataforma Kahoot, serve como uma ferramenta útil na revisão de conceitos, avaliação preliminar de conteúdos e engajamento dos alunos na resolução de exercícios.

\section{Considerações Finais}

Este trabalho apresenta um relato de experiência de uma atividade elaborada na plataforma digital Kahoot e a análise de seu potencial na aprendizagem dos alunos. Percebeu-se a partir das respostas apresentadas que o Kahoot apresentou algumas limitações de uso, assim como no trabalho de Sande \& Sande (2018), um exemplo é à necessidade de disponibilidade da Internet em sala de aula, entretanto, assim como com estes autores, a experiência com o Kahoot despertou o interesse e aumentou o estímulo nos alunos deixando o aprendizado mais atraente e divertido. Assim como no trabalho de Alves \& Roza (2018), os resultados encontrados indicam motivação dos alunos e a aprendizagem dos conteúdos. Desta forma, a percepção e interesse dos alunos foi positiva diante da experiência o que a coloca em um patamar de estratégia válida $\mathrm{e}$ recomendada para o ensino.

Perez et al. (2018), afirmam que o Kahoot é uma ferramenta dinâmica e valiosa como instrumento de avaliação, motivação e engajamento dos estudantes no processo de ensino-aprendizagem. Para Fardo (2013), os elementos dos games, dispõem de ferramentas valiosas na criação de experiências significativas para os alunos, impactando de forma positiva na experiência educacional dos indivíduos, potencializando a participação e a motivação dos indivíduos. Este estudo mostrou que a utilização do Kahoot na educação, afetou as atitudes dos alunos, como por exemplo: despertou prazer em classe e gerou experiências de aprendizagens novas e positivas.

Sendo assim, os professores podem adotar essa estratégia de ensino como metodologia que contribua melhorando o aprendizado. Pode-se afirmar com esta experiência que a maioria dos estudantes gostaram de participar da atividade. Assim, pretende-se replicar está em outras turmas, buscando novas constatações relevantes.

\section{Referências Bibliográficas}

Alves, N. A.; Roza, R. H. (2018). Gamificação no ensino de administração: o uso da plataforma Kahoot em uma disciplina de gestão de projetos. Revista Tecnologias na Educação, Ano 10, v. 25.

Amico, M. R. A., Pra, R., Moraes, J. P. (2017). As aplicações do Kahoot como tecnologia educativa. In: $22^{\circ}$ Seminário de Educação, Tecnologia e Sociedade, Taquara, RS. Revista Educacional Interdisciplinar (REDIN), v. 6, n. 1, p. 1-12.

Burke, B. (2015). Gamificar: como a gamificação motiva as pessoas a fazerem coisas extraordinárias. Tradução Sieben Grupe. Editora DVS. São Paulo.

Coil, D. A.; Ettinger, C. L. \& Eisen, J. A. (2017). Gut Check: The evolution of an educational board game. PLOS Biology, 15(4), e2001984.

Dellos, R. (2015). Kahoot A digital game resource for learning. International Journal of Instructional Technology and Distance Learning, 12(4), p. 49-52.

Deterding, S.; Dixon, D.; Khaled, R.; Nacke, L. (2011). From game design elements to gamefulness: defining gamification. In: Proceedings of the 15th International Academic MindTrek Conference - MindTrek'11, p. 9-11. 
VIII Congresso Brasileiro de Informática na Educação (CBIE 2019)

Anais do XXV Workshop de Informática na Escola (WIE 2019)

Dicheva, D.; Dichev, C.; Agre, G.; Angelova, G. (2015). Gamification in Education: A Systematic Mapping Study. Educational Technology \& Society. v. 18, n. 3, p. 1-14.

Domínguez, A.; Saenz-De-Navarrete, J.; De-Marcos, L.; Fernández-Sanz, L.; Pagés, C.; Martínez-Herráiz, J.J. (2013). Gamifying learning experiences: Practical implications and outcomes. Computers \& Education. 63. p. 380-392.

Fardo, M. L. (2013). A Gamificação aplicada em ambientes de aprendizagem. RENOTE Revista Novas Tecnologias na Educação, v. 11, n. 1, p. 1-9.

Faria, V. P; Costa, H.; Parreira Junior, P. A. (2016). eQuest: Um Sistema de Resposta para Estudantes Gamificado. In: Congresso Brasileiro de Informática na Educação. p. 280-287.

Figueiredo, M.; Paz, T.; Junqueira, E. S. (2015). Gamificação e educação: um estado da arte das pesquisas realizadas no Brasil. In: Congresso Brasileiro de Informática na Educação. p. 1154-1163.

Gazotti-Vallim, M. A. (2017). Vivenciando inglês com Kahoot. The ESPecialist: Descrição, Ensino e Aprendizagem, 38(1), p. 1-18.

Kahoot. (2018). What is Kahoot. Disponível em: https://kahoot.com/what-is-kahoot/ Acesso em 02 de Mar.

Kapp, K. M. (2012). The gamification of learning and instruction: game-based methods and strategies for training and education. San Francisco: Pfeiffer.

Lee, J. J.; Hammer, J. (2011). Gamification in Education: What, How, Why Bother? Academic Exchange Quarterly. v. 15, p. 1-5.

Morrison, B. B.; Disalvo, B. (2014). Khan academy gamifies computer science. In: Proceedings of the 45th ACM Technical Symposium on Computer Science Education - SIGCSE '14, p. $39-44$.

Pereira, S. R. C.; Pimentel, E. P. (2014). Laboratório Virtual Gamificado para o Ensino de Química em Dispositivos Móveis. In: Workshop Sobre Tecnologias Móveis Na Educação. p. 396-405.

Perez, P. V.; Schimidt, T. C. G.; Santos, C. F. (2018). Kahoot como ferramenta de revisão de conteúdo em neurociências. Congresso Internacional de Educação e Tecnologias. p. 1-9.

Rocha, P. S. R.; Lima, R. W.; Macedo, R. L.; Leite, C. R. M. Neto, F. M. M. (2016). Gamificação: Um aplicativo para o ensino da Língua Brasileira de Sinais. In: V Congresso Brasileiro de Informática na Educação - CBIE 2016, p. 896-900.

Rodríguez-Fernández, L. (2017). Smartphones y aprendizaje: el uso de Kahoot en el aula universitaria. Revista Mediterránea de Comunicación, v. 8, n. 1, p. 181-190.

Romio, T.; Paiva, S. C. M. (2017). Kahoot e GoConqr: uso de jogos educacionais para o ensino de matemática. Scientia Cum Industria, v. 5, n. 2, p. 90-94.

Sande, D.; Sande, D. (2018). Uso do Kahoot como ferramenta de avaliação e ensinoaprendizagem no ensino de microbiologia industrial. Holos, Ano 34, v. 1, p. 170-179.

Santaella, L.; Feitoza, M. (2009). Mapa do jogo: a diversidade cultural dos games. São Paulo, SP: Cengage Learning.

Silva, J. B. Da; Andrade, M. H.; Oliveira, R. R. De; Sales, G. L.; Alves, F. R. V. (2018). Tecnologias digitais e metodologias ativas na escola: o contributo do Kahoot para gamificar a sala de aula. Revista Thema, v 15, n 2, p. 780-791.

Tardif, M. (2011). Saberes docentes e formação profissional. 12 ed. Petrópolis, RJ: Vozes.

Trivinos, A. N. S. (1987). Introdução à pesquisa em Ciências Sociais: a pesquisa qualitativa em educação. São Paulo: Atlas.

Wang, A. I. (2015). The wear out effect of a game-based student response system. Computers and education. vol. 82, p. 217-227.

Yapici, İ. Ü.; Karakoyun, F. (2017). Gamification in Biology Teaching: A Sample of Kahoot Application. Turkish On-line Journal of Qualitative Inquiry, v. 8, n. 4, p. 396-314.

Yin, R. K. (2003). Case Study Research: Design and Methods. 3ed. Thousand Oaks, CA: Sage. 